\title{
Numerical evaluation of the seismic performance of thin reinforced concrete wall buildings representative of the industrialized building
} system

\author{
Eduar Cuesvas $^{a *}$ (D) , Roger Ortega ${ }^{a}$ (D) , Johannio Marulanda ${ }^{\text {(D) }}$, Peter Thomson ${ }^{a}$ (D) Gilberto Areiza $^{a}$ (D), \\ Alejandro $\mathrm{Cruz}^{\text {a }}$
}

a Escuela de Ingeniería Civil y Geomática, Universidad del Valle. Ciudad universitaria Meléndez, Calle 13, 100-00 Cali, Edificio E48, Cali, Colombia. eduar.cuesvas@correounivalle.edu.co, ortega.roger@correounivalle.edu.co, Johannio.marulanda@correounivalle.edu.co, peter.thomson@correounivalle.edu.co,gilberto.areiza@correounivalle.edu.co, alejandro.cruz@correounivalle.edu.co

* Corresponding author

https://doi.org/10.1590/1679-78256759

\begin{abstract}
The industrialized building system has specific characteristics that set it apart from the conventional concrete wall system, namely, a reduced wall thickness, the use of electro-welded wire mesh, and a lack of boundary element confinement. These conditions have attracted the interest of researchers, who have developed various experimental programs to evaluate the behavior of these walls. However, evidence on the seismic performance of buildings remains scarce. In this study, the performance of 5-, 8- and 12-story buildings was evaluated by nonlinear chronological analysis. Numerical models were constructed using the Shell Layered element of the ETABS software and adjusted based on the results from tests of isolated walls and the periods of one of the buildings identified in an ambient vibration test. The findings suggest that these buildings may fail to meet the life safety performance level in high seismic hazard areas.
\end{abstract}

\section{Keywords}

thin walls, industrialized building system, seismic performance, parametric analysis, Shell Layered.

\section{Graphical abstract}
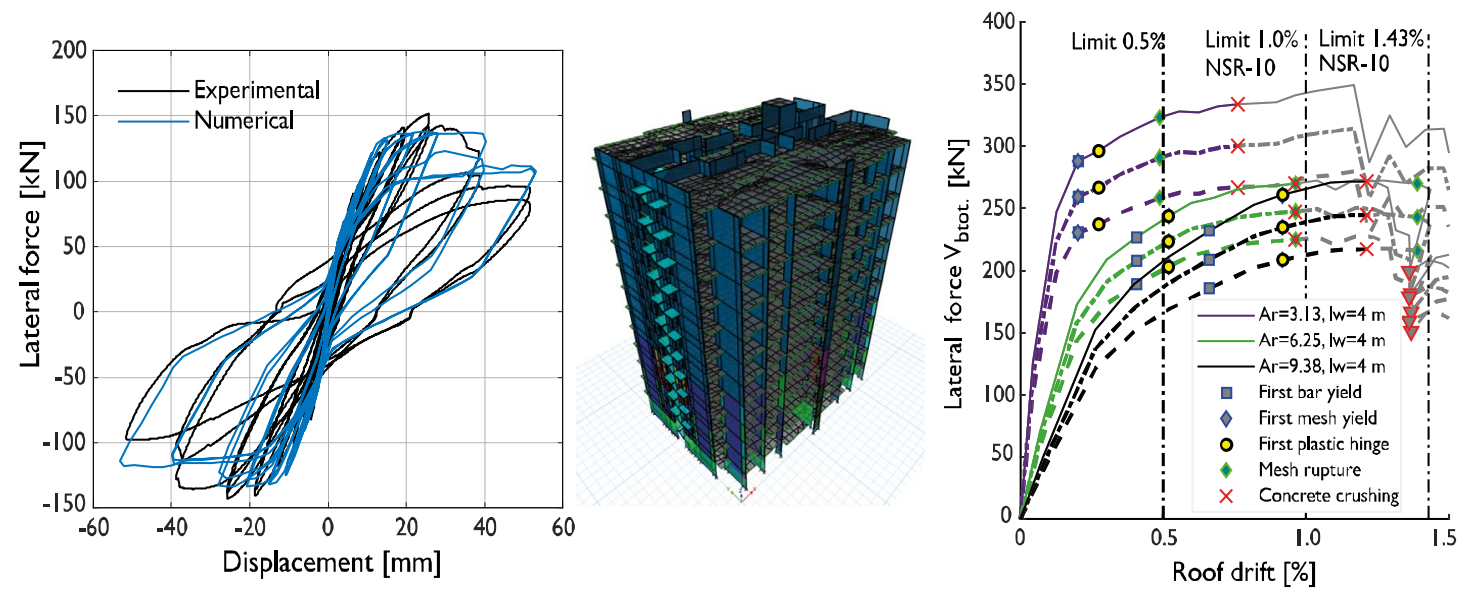

Received September 28, 2021. In revised form October 06, 2021. Accepted December 07, 2021. Available online December 10, 2021 https://doi.org/10.1590/1679-78256759

(a) Latin American Journal of Solids and Structures. ISSN 1679-7825. Copyright (C) 2021. This is an Open Access article distributed under the terms of the Creative Commons Attribution License, which permits unrestricted use, distribution, and reproduction in any medium, provided the original work is properly cited. 


\section{INTRODUCTION}

The industrialized building system of thin reinforced concrete wall (TRCW) buildings is one of the most used housing construction methods in Colombia and other Latin American countries (DANE, 2021; Gonzales \& López-Almansa, 2012). This structural system consists of cast-in-place concrete walls and floor slabs that are usually poured monolithically. The main characteristic of this system is a reduced wall thickness, ranging from 80 to $150 \mathrm{~mm}$, which results in high slenderness ratios. Low reinforcement ratios of electro-welded wire mesh (WWM), ranging from 0.12 to $0.7 \%$, are used in the wall web and generally arranged in a single layer in the center of the section. The ends of the walls are longitudinally reinforced, sometimes, with conventional ductile bars and with hooks or stirrups as transverse reinforcements; however, due to the limited thickness, confinement at the ends of these bars is considered ineffective (Arteta, 2015). In Colombia, in recent years, a large number of low- and medium-rise buildings with these characteristics have been constructed in high and intermediate seismic hazard areas because the Colombian Code for Earthquake-Resistant Construction NSR-10 (AIS, 2010) does not specify the minimum thickness of walls and their boundary elements or restrict the use of electrowelded wire mesh.

In recent years, the response of isolated walls, which are representative of the industrialized building system, to cyclic lateral loading has been evaluated experimentally (Quiroz et al., 2013; Rosso et al., 2015; Blandón et al., 2018; Blandón \& Bonett, 2020; Ortega et al., 2021). These studies demonstrated that the displacement capacity of thin and slender walls is limited and considerably lower than the drift limit of $1.43 \%$, which is defined for designs based on cracked sections according to NSR-10. High stiffness degradation from low drift levels, rupture of the electro-welded wire mesh due to concentrated damage at the wall-foundation interface, buckling of longitudinal reinforcements at the ends, and concentration of plasticity at reduced heights (up to three times the wall thickness), have been observed. Also, the susceptibility of these walls to out-of-plane buckling failure was confirmed. Concomitantly with these experimental programs, the global performance of TRCW buildings has been evaluated numerically. Gonzales and López-Almansa (2012) evaluated the vulnerability of seven 4- and 5-story buildings, located in Peru, using nonlinear static (Pushover) and chronological analyses. The findings indicated that their seismic resistance was insufficient and that for the Life Safety performance level, four of the seven buildings exhibited inappropriate behavior. The Colombian Earthquake Engineering Research Network (CEER) has developed tests for isolated walls and various theoretical and numerical approaches to analyze the performance of TRCWs and WWMs (Carrillo et al., 2018; CEER, 2018) in an effort to propose changes to current standards in Colombia. CEER evaluated the performance of this system by modeling six 5-, 10- and 15-story buildings, designed according to NSR-10, with 80-, 100-, 120- and 150-mm-thick walls, using nonlinear static, nonlinear dynamic, and incremental dynamic analyses. The buildings showed limited ductility, concentrated plasticity near the base, and WWM rupture. These authors concluded that the structural system is inadequate for tall buildings and that the current regulatory requirements are insufficient to guarantee good seismic performance. Arroyo et al. (2021) numerically evaluated the performance of a 6-story TRCW building with 100-mm-thick walls reinforced with WWM. These authors developed a nonlinear model of the building and an equivalent model reinforced with ductile bars. The results indicated that the dominant failure mode in the WWM building was reinforcement rupture, whereas using ductile reinforcements markedly improved the seismic performance and considerably reduced the probability of failure, which was evaluated for ground movements scaled to the maximum credible earthquake. Therefore, this system is not recommended for medium-rise buildings in areas of intermediate-to-high seismic hazard.

Despite these results, and given that the actual seismic performance of this system remains unknown, developing numerical simulations to help evaluate its response and estimating the seismic hazard of TRCW buildings is still necessary. Accordingly, three 5-, 8- and 12-story buildings, which are representative of the industrialized building system and located in the city of Santiago de Cali in Colombia, were analyzed in this study. Nonlinear numerical models of the buildings were developed and adjusted based on experimental results from isolated walls and an ambient vibration test, which was employed to identify the dynamic properties of one of the structures. The seismic performance of the buildings was evaluated using nonlinear chronological analysis by measuring their response in terms of global and local parameters. Lastly, the effects of variables such as the aspect ratio, the longitudinal reinforcement ratio at the boundaries, and the thickness of the walls on their response to lateral loading were assessed by parametric analysis.

\section{METHODOLOGY}

The seismic performance of the TRCW structural system was evaluated using a database of 121 buildings located in the cities of Santiago de Cali and Popayán in Colombia, in high seismic hazard areas (Ortega et al., 2019; Palacios, 2017). From the structural drawings and calculation reports, data were extracted for a statistical analysis to define the typical parameters of this structural system and to establish the conditions for cyclic tests of isolated walls in an ongoing 
experimental program at Universidad del Valle. Based on the experimental results from thin wall tests (Ortega et al. 2021), in addition to the hysteretic responses of other walls with similar characteristics obtained from renowned experimental campaigns (Oesterle et al. 1976, Quiroz et al. 2013, and Thomsen IV \& Wallace 1995), a numerical model was constructed and calibrated to estimate the response of TRCWs subjected to cyclic lateral loading (Cuesvas et al., 2020). The numerical models were implemented in the ETABS software using the nonlinear function of "Shell Layered" elements.

Figure 1 shows two of the variables evaluated in the statistical analysis for the buildings in the database. The first variable is the wall density, which was calculated as the ratio between the floor area of the walls of the first floor and the floor area of the building in the two mains directions. The second variable is the distribution of the slenderness ratios, defined as the ratio between the clear height and the thickness $\left(h_{w} / t_{w}\right)$. The average wall density was $2 \%$ and $2.5 \%$ in the longitudinal $(x)$ and transverse $(y)$ directions, respectively, and the typical slenderness ratio for these buildings was 25 .

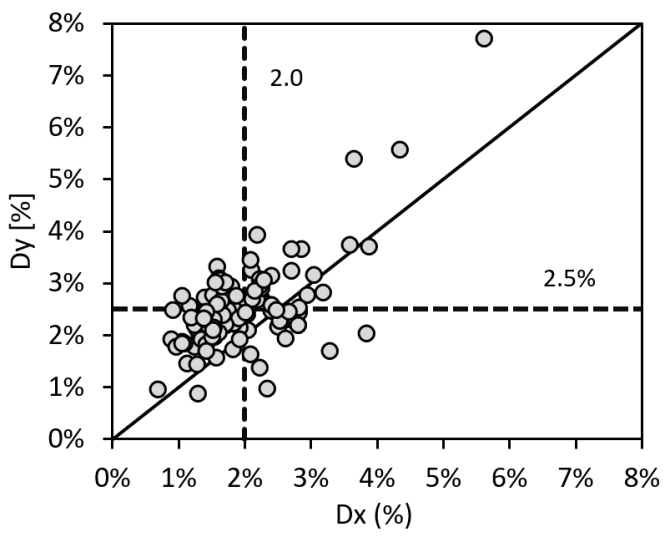

a)

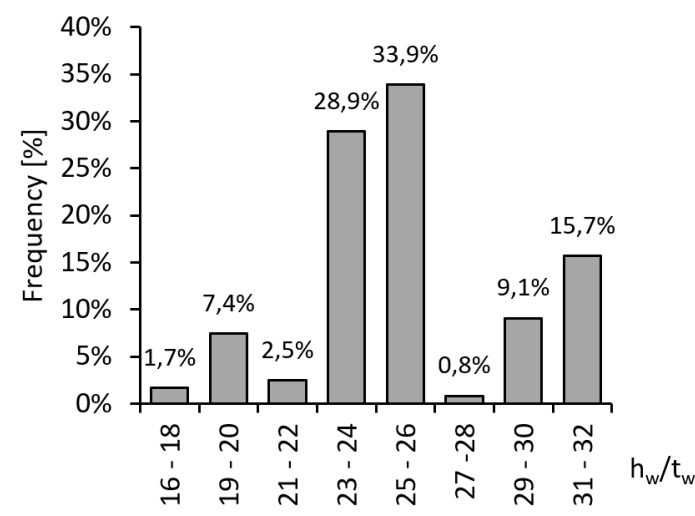

b)

Figure 1. Database analysis: a) wall density in the two mains directions; b) slenderness ratios.

Subsequently, 18 linear numerical models of representative buildings from the database were constructed, and typical values of variables such as the axial load ratio (ALR), the ratio between the bending moment and shear (M/V), the fundamental period, aspect ratio, and the interstory and roof drift were identified, among others (Ortega et al. 2019). From this analysis, three representative 5-, 8- and 12-story buildings were selected and labeled E1, E2, and E3, respectively. Nonlinear numerical models were constructed for these buildings and adjusted in two ways. At a global level, the models were adjusted based on the experimental results from an ambient vibration test in one of the buildings analyzed in this study. This test made it possible to assess the actual dynamic properties and to adjust the numerical model by varying the parameters related to the degree of cracking in the structure, which were extrapolated to the other two buildings. At a local level, the models were adjusted to simulate the inelastic response of the walls of the buildings using the modeling and calibration parameters determined for the numerical model of isolated walls based on the hysteretic response measured in the experimental tests.

Based on the adjusted models, the seismic performance of the buildings was evaluated in two stages. In the first stage, the seismic vulnerability was diagnosed, according to NSR-10. In the second stage, the seismic performance was evaluated by nonlinear chronological analysis; seismic microzoning records of Santiago de Cali were used (INGEOMINAS, 2005), and the response of the buildings in terms of parameters such as interstory drift, wall base rotation, and materials strains, was assessed. To study some of the variables with the strongest effect on the wall seismic performance, a parametric analysis was performed. In total, 140 isolated TRCW models were evaluated by nonlinear static analysis (pushover) in 5-, 10- and 15-story walls, with thicknesses ranging from 80 to $150 \mathrm{~mm}$ and the longitudinal reinforcement ratio at the boundary elements ranging from 0 to $4 \%$.

\section{DESCRIPTION OF THE NUMERICAL MODELS}

Numerical models of isolated walls and buildings were constructed with the Shell Thin and Shell Layered elements in ETABS for elastic and inelastic elements, respectively. The inelastic models were designed by representing the transverse section of an element, in the thickness direction, in different equivalent layers, as shown in Figure 2 . Thus, a reinforced concrete wall can be subdivided into parallel layers, with some layers corresponding to confined or unconfined concrete and other layers corresponding to reinforcement steel. 
In numerical models, the stress-strain curves of conventional concrete and ductile reinforcement steel were defined using models developed by Mander et al. (1988) and Park and Paulay (1975), respectively. The stress-strain curve of nonductile WWM was calculated using equation (1), which was proposed by Mirza and Mac-Gregor (1981). In isolated walls, the mechanical properties of the materials were defined according to laboratory reports. In the models of the buildings, the stress-strain curves of unconfined concrete and reinforcement steel were constructed using the parameters shown in Table 1. The elastic modulus of concrete, $E_{c}$, was estimated to be $3900 \mathrm{Vf}^{\prime}{ }_{c}(\mathrm{MPa})$.

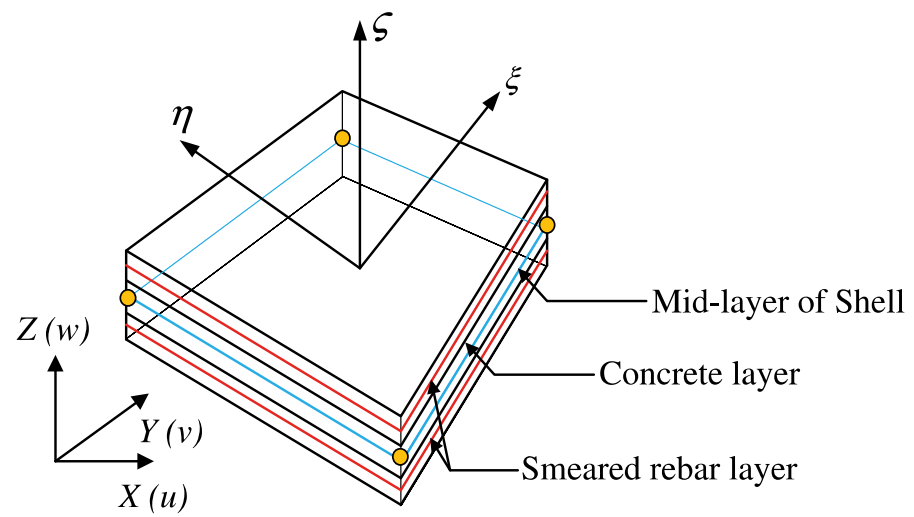

Figure 2. Representation of concrete and reinforcement steel layers in a Shell Layered element (Lu et al., 2014).

$\varepsilon=\frac{f}{E_{s}}+\left(\varepsilon_{s u}-\frac{f}{E_{S}}\right)\left(\frac{f}{f_{u}}\right)^{20}$

Table 1. Properties of the materials.

\begin{tabular}{|c|c|c|c|}
\hline Parameter & E1 & E2 & E3 \\
\hline Concrete compression strength, $\mathrm{f}_{\mathrm{c}}^{\prime}(\mathrm{MPa})$ & 21 & 21 & 21,28 \\
\hline Elasticity modulus of concrete, $E_{c}(\mathrm{GPa})$ & 17.8 & 17.8 & 18,21 \\
\hline Yield strength of the bars, $\mathrm{f}_{\mathrm{y}}(\mathrm{MPa})$ & 420 & 420 & 420 \\
\hline Yield strength of the meshes, $\mathrm{f}_{\mathrm{ywwm}}(\mathrm{MPa})$ & 500 & 500 & 500 \\
\hline Ultimate strength of the bars $f_{u}(\mathrm{MPa})$ & 525 & 525 & 525 \\
\hline Ultimate strength of the meshes, $\mathrm{f}_{\mathrm{uwwm}}(\mathrm{MPa})$ & 630 & 630 & 630 \\
\hline Peak compressive strain of concrete, $\varepsilon_{\mathrm{co}}$ & 0.002 & 0.002 & 0.002 \\
\hline Ultimate compressive strain of concrete, $\varepsilon_{\mathrm{cu}}$ & 0.004 & 0.004 & 0.004 \\
\hline Rupture strain of the bars, $\varepsilon_{\mathrm{su}}$ & 0.12 & 0.12 & 0.12 \\
\hline Rupture strain of the meshes, $\varepsilon_{\text {suwwm }}$ & 0.015 & 0.015 & 0.015 \\
\hline
\end{tabular}

The hysteretic performance was modeled using the pivot hysteresis model, which was proposed by Doweel et al. (1998), and is recommended for reinforced concrete members (CSI, 2017). This model can simulate the pinching effect, control stiffness degradation, and enable the application of non-symmetry in hysteretic loops. The behavior of this model is based on the fact that the loading and unloading directions are directed toward specific points, which are termed pivot points, in the force-deformation plane.

\subsection{Isolated numerical models}

Figure 3a shows the superposition of the experimental and numerical hysteresis curves for one of the walls modeled in this study (M1R10); the wall was tested at the University of Valle by Ortega et al. (2021). The M1R10 wall had a length of $1200 \mathrm{~mm}$, a height of $2700 \mathrm{~mm}$, and a thickness of $100 \mathrm{~mm}$. A single electro-WWM reinforcement was used in the web and conventional reinforcement bars in the ends. The longitudinal reinforcement ratio in the web and the boundaries were $0.25 \%$ and $1.46 \%$, respectively. The tests were performed with a shear span (M/V $\left.\cdot I_{\mathrm{w}}\right)$ of 2.1 and an axial load ratio of $9 \%\left(A L R=P / f^{\prime}{ }_{c} l_{w} t_{w}\right)$. The wall was subjected to a protocol of displacements measuring 3.6, 6.0, 8.4, 12, 18, $24,36,48$, and $60 \mathrm{~mm}$ in amplitude, where $M$ and $V$ are the bending moment and shear, respectively, and $I_{w}$ is the wall length. $P$ is the axial loading, $f^{\prime}{ }_{c}$ is the compressive strength of concrete, and $t_{w}$ is the wall thickness. 


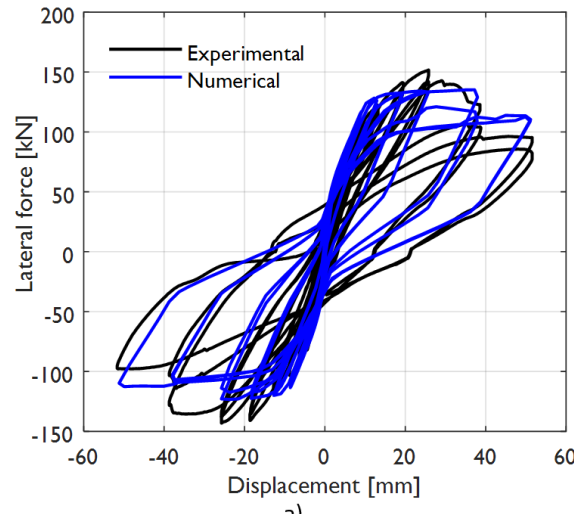

a)

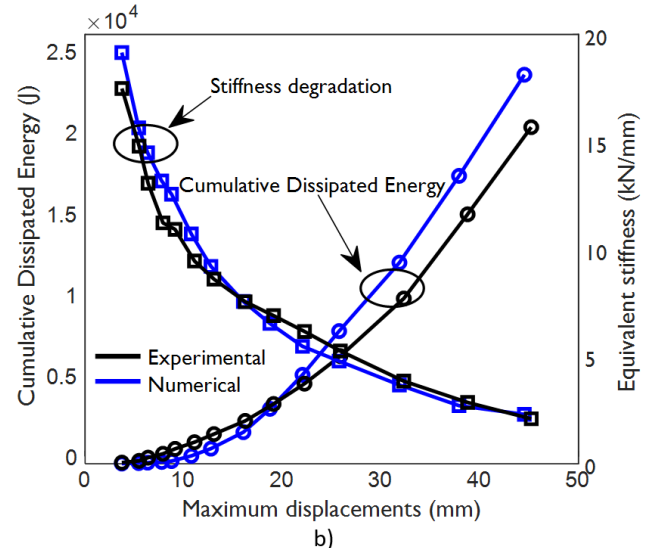

b)

Figure 3. Comparison of the numerical and experimental responses of wall M1R10: a) hysteresis curve; b) stiffness degradation and cumulative dissipated energy.

The models were defined with nonlinear behavior in the wall plane and linear behavior for the out-of-plane component. The results from the numerical simulation of isolated walls with this formulation show that the ETABS Shell Layered model is a practical tool for TRCW modeling because this model accurately captured the global hysteretic response of the walls in terms of the lateral resistance versus the displacement, with a good degree of approximation to stiffness degradation and energy dissipation (Figure $3 \mathrm{~b}$ ) and a moderate computational cost. A detailed description of the first stage of this study is available from Cuesvas et al. (2020).

\subsection{Models of TRCW buildings}

The buildings termed E1, E2 and E3 are located in Santiago de Cali city, in a high seismic hazard area in Colombia, on a type D soil (AIS, 2010) and seismic microzones 4D and 4B (INGEOMINAS, 2005), respectively. Building E1 is a 5-story structure with $80-\mathrm{mm}$-thick walls without boundary elements. The wall web reinforcement consists of a single layer of electro-WWM located in the middle of the section. This structural configuration accounts for $23 \%$ of the buildings in the database. Building E2, an 8-story structure, consists of 100-mm-thick walls, with WWM reinforcement in the web arranged in a single layer and boundary elements. This structural configuration accounts for $39 \%$ of the buildings in the database. Building E3 is a 12-story structure, with 120-mm-thick walls, electro-WWM reinforcement in the web arranged in a single layer, and boundary elements. This configuration accounts for $8 \%$ of the buildings in the database. The floor slabs in the three buildings consist of a 100-mm-thick solid plate. The term "boundary elements" refers to ductile reinforcements concentrated at the ends of some walls and supported by hooks or stirrups. These elements have the same thickness as the walls and rarely meet the detailing requirements specified by NSR-10. Table 2 summarizes the main properties of the buildings.

Table 2. Properties of the TRCW buildings.

\begin{tabular}{|c|c|c|c|c|c|c|c|c|c|}
\hline Building & $\mathbf{N}$ & $t_{w}(m m)$ & $H(m)$ & $h_{w}(m)$ & $h_{w} / t_{w}$ & $A\left(m^{2}\right)$ & $D_{x}(\%)$ & $D_{Y}(\%)$ & $\begin{array}{c}\text { Type of } \\
\text { reinforcement }\end{array}$ \\
\hline E1 & 5 & 80 & 12.1 & 2.42 & 30.2 & 340.4 & 2.3 & 2.5 & WWM \\
\hline E2 & 8 & 100 & 20 & 2.40 & 24.0 & 770.7 & 1.4 & 2.3 & WWM and bars \\
\hline E3 & 12 & 120 & 30.6 & 2.45 & 20.4 & 445.0 & 1.9 & 2.7 & WWM and bars \\
\hline
\end{tabular}

Note: $\mathrm{N}$ : number of stories, $\mathrm{t}_{\mathrm{w}}$ : wall thickness, $\mathrm{H}$ : total height, $\mathrm{h}_{\mathrm{w}}$ : interstory height, $\mathrm{A}$ : floor area, $\mathrm{D}_{\mathrm{x}}, \mathrm{D}_{\mathrm{y}}$ : wall density in the $\mathrm{X}$ - and $\mathrm{Y}$-directions.

In the models, the walls resist axial loads, bending, and shear in their plane, with nonlinear behavior. A linear behavior for out-of-plane bending was assumed. The slabs were considered elastic, stiff diaphragms that allow loads to be transferred to the wall system. The gravitational load and seismic mass for the structural analysis correspond to the 1.0D + 0.25L combination (FEMA 356, 2000), where D and L represent dead and live loads, respectively. A Rayleigh damping of $5 \%$ was defined for the analysis. Figure 4 shows the models and plan view of the buildings. 

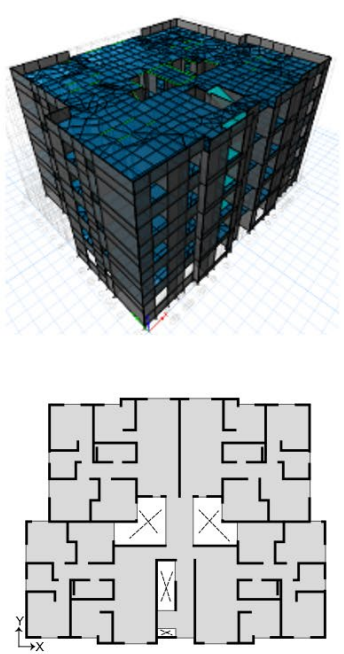
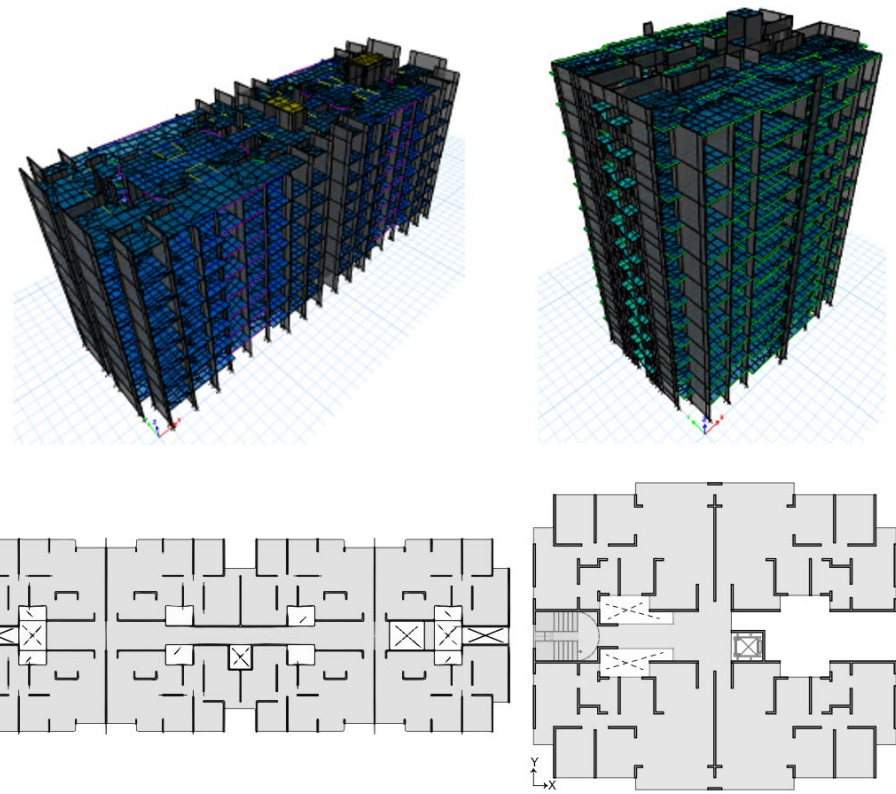

c)

Figure 4. Numerical models and plan view of the buildings, a) E1, b) E2 and c) E3.

\section{DESCRIPTION OF THE NUMERICAL MODELS}

The ambient vibration test was performed in building E2 (Figure 5a) to adjust its numerical model and to determine the global parameters for adjusting the models of the other buildings, E2 and E3. The test consisted of acquiring accelerations due to ambient vibration at relevant points of the structure. For this purpose, uniaxial and triaxial sensors were used (Figure $5 \mathrm{~b}$ ), and readings were taken on the sixth and eighth story of the building.

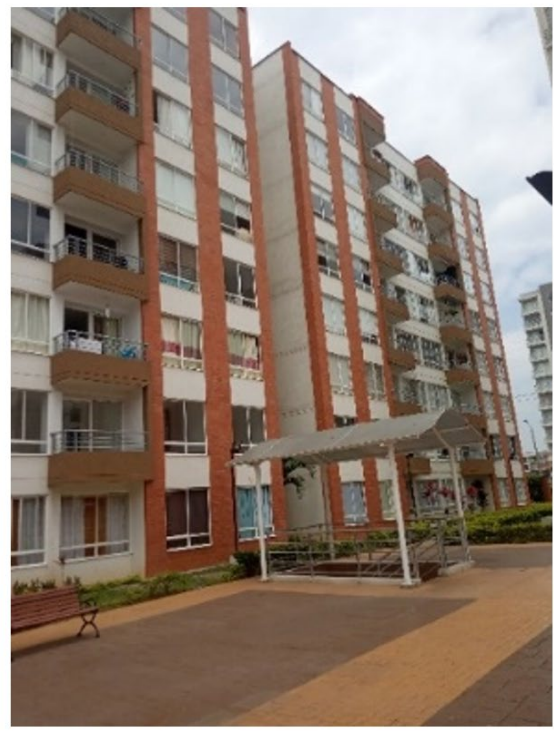

a)

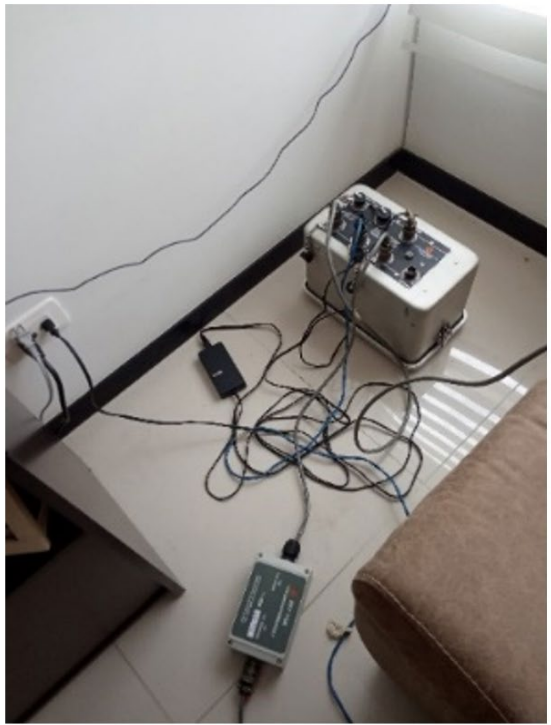

b)

Figure 5. Experimental vibration test: a) instrumented building, b) triaxial accelerometer.

The recorded signals were processed and analyzed using three methods for identifying dynamic properties. The first method involved Power Spectral Density (PSD) functions, and the second and third methods used Stochastic Subspace Identification (SSI) and the Natural Excitation Technique with Eigensystem Realization Algorithm (NExT-ERA), respectively. Figure 6 shows the identification, based on the PSD function, of the two predominant natural frequencies of the structure, and Table 3 shows the fundamental periods determined using the three techniques for the first two modes of vibration of building E2. 

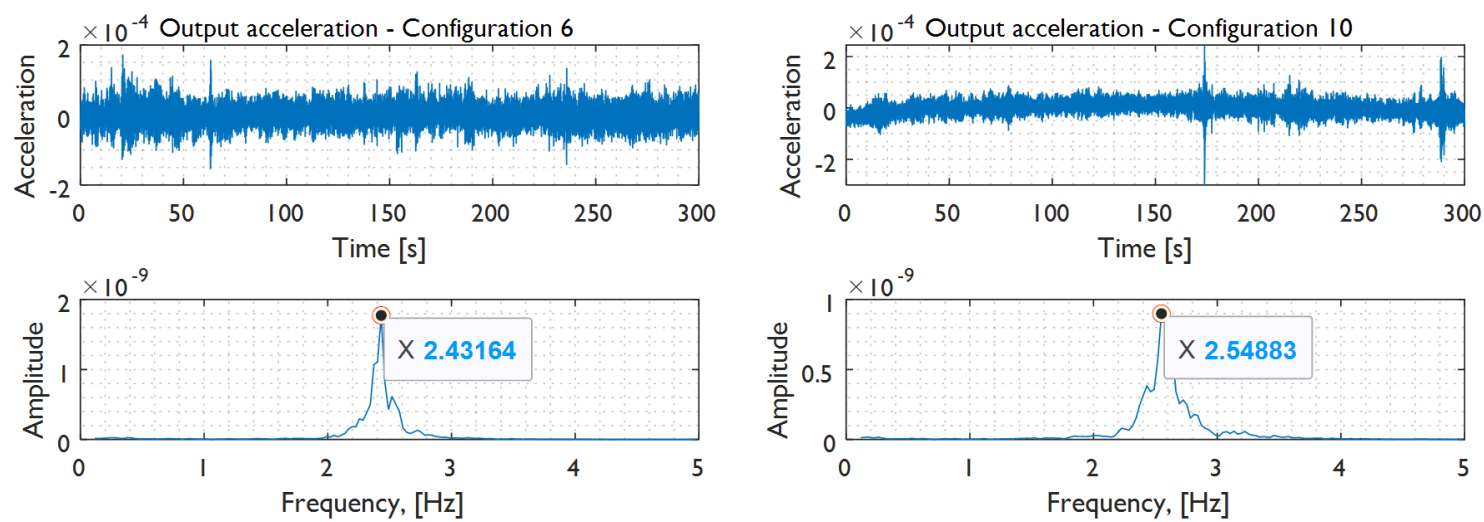

Figure 6. Identification of the natural frequency for the first two mode vibration of building E2.

Table 3. Experimental fundamental periods.

\begin{tabular}{cccc}
\hline Mode & T - PSD (s) & T - SSI (s) & T - NExT-ERA (s) \\
\hline 1 & 0.411 & 0.413 & 0.407 \\
2 & 0.392 & 0.390 & 0.385 \\
\hline
\end{tabular}

The numerical model of the building was adjusted by modifying the parameters that control the inelastic response of the walls and the level of cracking in the walls and beams. The process was performed using an application programming interface (API) between the programs MATLAB and ETABS, which facilitated the variation in these parameters within reasonable ranges. The cracking levels assessed after adjusting the model were approximately $50 \%$ for walls and $35 \%$ for beams. Table 4 summarizes the results from the adjustment of the model of building E2 regarding the fundamental period, T. The nonlinear behavior, modeled with the Shell Layered element, was only implemented in the walls of the lower third of the building, assuming a linear behavior in the two upper thirds. These parameters were used in the models of buildings E1 and E3.

Table 4. Comparison of experimental and analytical fundamental periods of the adjusted and unadjusted models.

\begin{tabular}{|c|c|c|c|c|c|}
\hline \multirow{2}{*}{ Mode } & \multirow{2}{*}{$\begin{array}{c}\text { Texp. } \\
\text { (s) }\end{array}$} & \multicolumn{2}{|c|}{ Unadjusted model } & \multicolumn{2}{|c|}{ Adjusted model } \\
\hline & & $T(s)$ & Error (\%) & $\mathrm{T}(\mathrm{s})$ & Error (\%) \\
\hline 1 & 0.413 & 0.362 & 12.3 & 0.411 & 0.50 \\
\hline 2 & 0.390 & 0.337 & 13.6 & 0.384 & 1.54 \\
\hline
\end{tabular}

\section{RESULTS}

\subsection{Seismic vulnerability assessment}

The seismic vulnerability of the buildings was diagnosed by following the procedure established in chapter A.10 of NR-10. This method consists of determining if the structural performance of a building in its current state meets the minimum requirements established in the standard in terms of the ratio between demand and capacity (D/C) when subjected to seismic events. For this purpose, the overstress (OSI) and flexibility (FlexI) indices of the structure were determined. OSI is expressed as the quotient between equivalent stresses and the effective strength of the structural element under such stresses. Similarly, Flexl is defined as the ratio between deflections or drifts and the corresponding limit allowed by NSR-10. For this evaluation, a spectral modal dynamic analysis of the linear models was performed by calculating the individual OSIs for each structural element and the general OSI of the building according to the largest individual OSIs and their incidence on the overall resistance. The inverse of the general OSI expresses the vulnerability of the building as a fraction of the strength that a properly designed new building should have. Similarly, the inverse of the general Flexl expresses the seismic vulnerability of the building as a fraction of the stiffness of a new construction in compliance with regulations.

The story drifts assessed by the elastic structural analysis are shown in Figure 7. The results indicate that the 12 story building E3 largely surpassed, in one of the directions, the drift limit of $1.43 \%$ established in NSR-10 for the analysis of cracked sections. The highest drift (2.15\%) occurred in the y-direction, which has a higher wall density, but this 
direction was more affected by the discontinuity in the floor diaphragm. The 5- and 8-story buildings E1 and E2 showed maximum drifts of 0.09 and $0.47 \%$, respectively, in the directions with the lowest wall density.

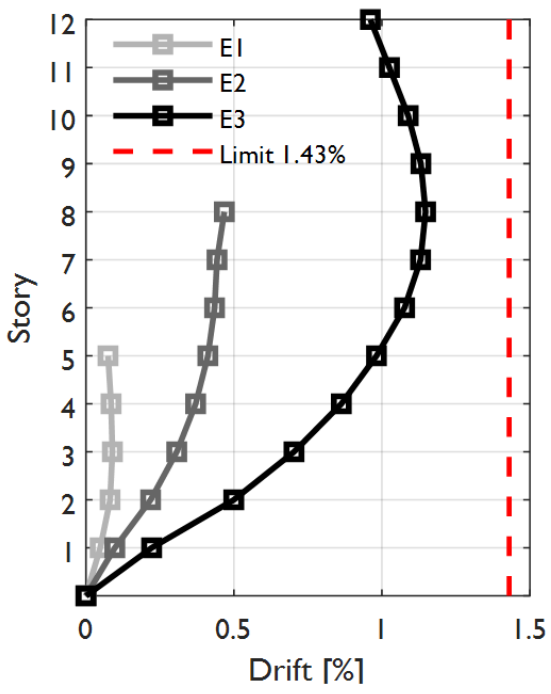

a)

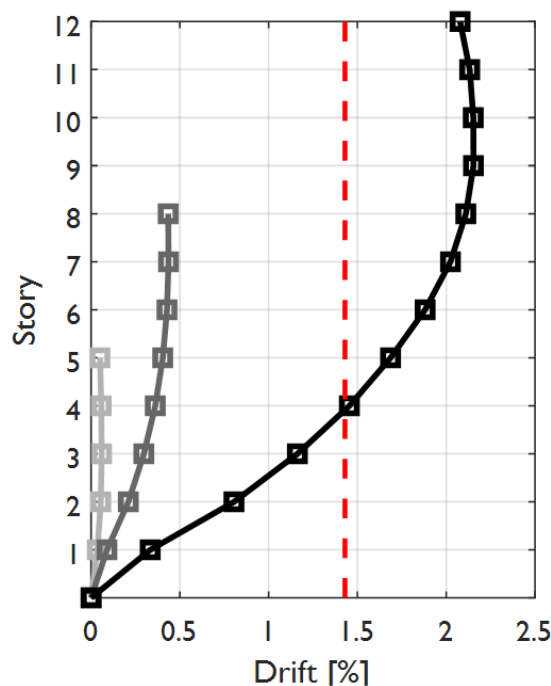

b)

Figure 7. Story drifts: a) earthquake in the $x$-direction, b) earthquake in the y-direction.

Table 5 summarizes the inverse of the OSI of the three most critical walls in each building for bending and shear demands and the inverse of the general Flexl. Figure 8 shows the general seismic vulnerability indices for each building. According to these indices, building E1 should perform acceptably when facing a seismic hazard, consistent with its design, because the inverses of the OSI and Flexl indicate that its strength and stiffness are higher than those required.

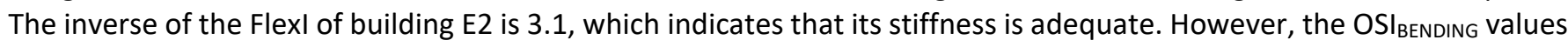
suggest that structural damage could occur in the event of a demand similar to the capacity of the design. In this building, ten of its walls have OSI BENDING values that are higher than 1.0. For building E3, the results of the three indices considered in this study suggest a considerable vulnerability. The inverses of the three indices show values below 1 , indicating that when facing a design demand, the structure would not have sufficient strength and rigidity. In this building, approximately $40 \%$ of the walls showed OSI BENDING values higher than 1.

Table 5. Seismic vulnerability indices according to NSR-10.

\begin{tabular}{|c|c|c|c|}
\hline \multirow{2}{*}{ Building } & \multicolumn{3}{|c|}{ Seismic vulnerability indices } \\
\hline & $1 / O S I_{\text {BENDING }}$ & $1 / O S I_{\text {SHEAR }}$ & 1/FlexI \\
\hline \multirow[t]{3}{*}{ E1 } & $1 / 0.585=1.71$ & $1 / 0.244=4.01$ & $1 / 0.063=16.0$ \\
\hline & $1 / 0.561=1.78$ & $1 / 0.236=4.88$ & \\
\hline & $1 / 0.383=2.61$ & $1 / 0.218=4.95$ & \\
\hline \multirow[t]{3}{*}{ E2 } & $1 / 1.37=0.73$ & $1 / 0.631=1.59$ & $1 / 0.327=3.10$ \\
\hline & $1 / 1.25=0.80$ & $1 / 0.625=1.60$ & \\
\hline & $1 / 1.20=0.83$ & $1 / 0.580=1.72$ & \\
\hline \multirow[t]{3}{*}{ E3 } & $1 / 4.867=0.20$ & $1 / 1.30=0.77$ & $1 / 1.58=0.63$ \\
\hline & $1 / 4.832=0.21$ & $1 / 1.25=0.80$ & \\
\hline & $1 / 3.267=0.31$ & $1 / 0.96=1.04$ & \\
\hline
\end{tabular}

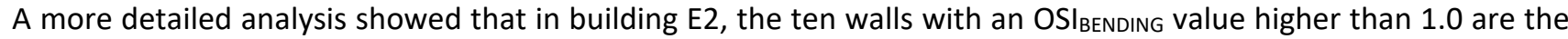
longest walls of the seismic resistance system, are mainly concentrated at the core and ends of the building and are oriented in the direction with the lowest wall density. For building E3, most walls with a bending index higher than 1 (i.e. $40 \%$ ) are located at the ends of the building and oriented in the y-direction, which is the most critical direction due to the discontinuity of the floor diaphragm. In building E1, the maximum values also occurred in the longest walls, but they did not reach values higher than 1. 


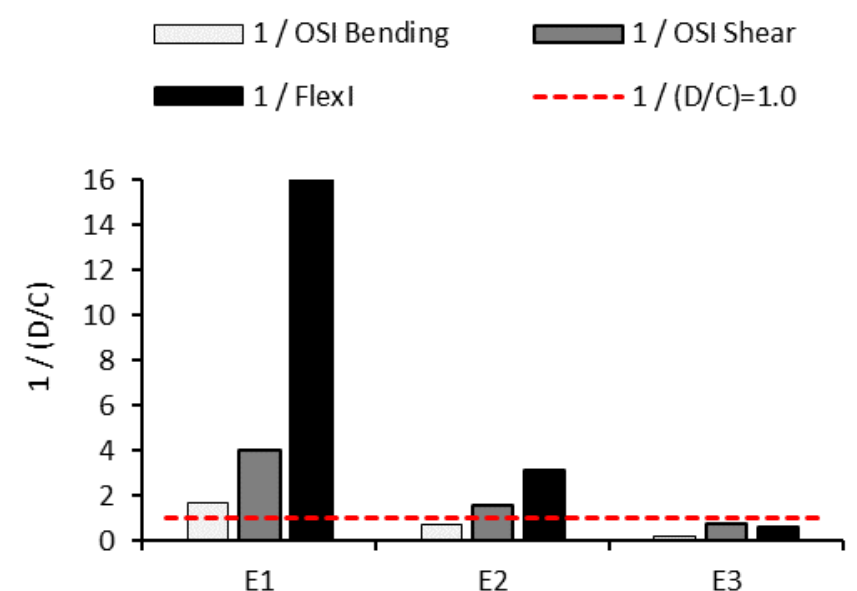

Figure 8. Seismic vulnerability indices of the buildings according to NSR-10.

\subsection{Seismic performance assessment}

Seismic performance was assessed considering a seismic demand consistent with the seismotectonic environment characteristic of the city of Santiago de Cali. The NSR-10 and ASCE/SEI 41-17 (2017) requirements were followed to select and scale the seismic signals. Table 6 shows the main properties of the seven accelerograms used in this study. Each pair of accelerograms, corresponding to the north-south and east-west components, were scaled with the same factor, so that the accelerograms did not individually have spectral ordinates lower than $80 \%$ of the design spectral ordinates in the range of periods between $0.8 \mathrm{~T}$ and $1.2 \mathrm{~T}$; and that the mean square root of the sum of the squares of the spectra of each accelerogram in the range of periods between $0.2 \mathrm{~T}$ and $1.5 \mathrm{~T}$ was not lower than the design spectral ordinates (Figure 9). T was determined as the fundamental period of the inelastic models of the buildings.

Table 6. Properties of seismic signals.

\begin{tabular}{cccccc}
\hline Earthquake & Date (dd/mm/yy) & Magnitude $(\mathbf{k m})$ & Type of fault & Scenario & Epicentral distance (km) \\
\hline 1. New Zealand (NZ) & $28 / 01 / 91$ & 5.8 & Reverse & Cortical & 24 \\
2. Italy (IT) & $26 / 09 / 97$ & 6.0 & Normal & Cortical & 21.6 \\
3. Kocaeli (KC) & $17 / 08 / 99$ & 7.51 & Strike slip & Cortical & 98.2 \\
4. Japan (JP) & $26 / 05 / 03$ & 7.0 & Reverse & Deep Subduction & 89 \\
5. Chile (CH) & $13 / 06 / 05$ & 7.9 & Reverse & Deep Subduction & 119 \\
6. Mexico (MX) & $19 / 09 / 85$ & 8.1 & Reverse & Shallow Subduction & 91 \\
7. Taiwan Smart1 (TS) & $14 / 11 / 86$ & 7.3 & Reverse & Shallow Subduction & 76 \\
\hline
\end{tabular}

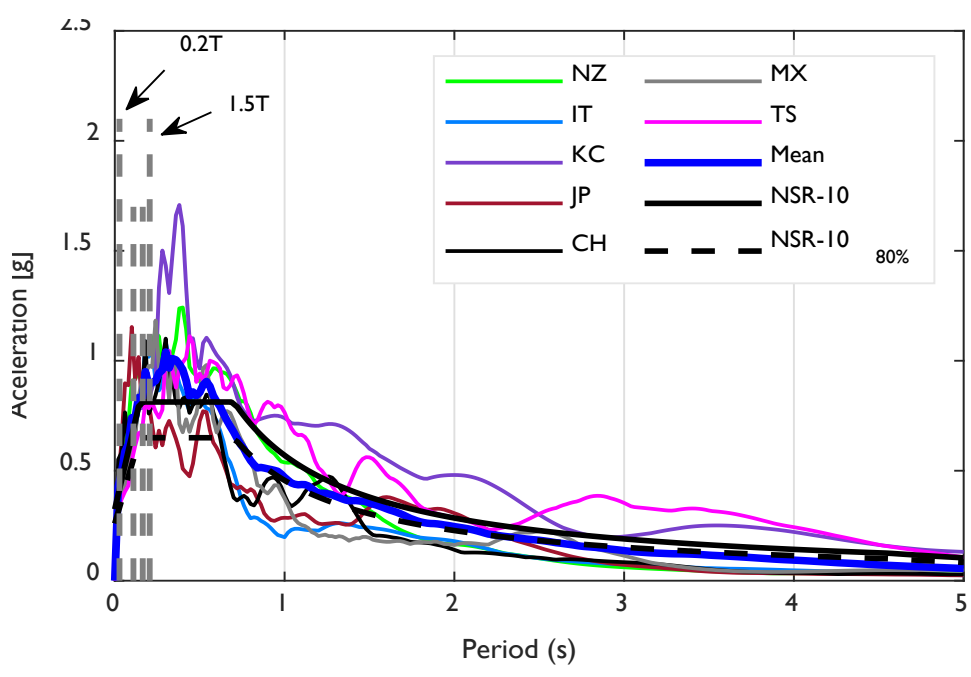

Figure 9. Response spectra of earthquakes scaled to the design spectrum for building E1. 
The building performance was assessed regarding local and global damage quantification parameters, such as strains in concrete and reinforcing steel, plastic hinge rotation at the base of the walls, and story drift. The proposed acceptance criteria (C), which are based on the experimental performance of concrete walls, are shown in Table 7. This analysis was performed for the life safety performance level because the seismic demand (D) was defined concerning the design spectrum of NSR-10, with a return period of 475 years.

Table 7. Parameters and acceptance criteria for seismic performance assessment of TRCW buildings.

\begin{tabular}{ccc}
\hline No. & Parameter & Limit value \\
\hline 1 & Plastic hinge rotation at the base of the walls, $\theta_{\mathrm{rp}}{ }^{*}$ and $\theta_{\mathrm{rp}}{ }^{* *}(\mathrm{rad})$ & 0.004 \\
2 & Story drift, $\Delta_{1}(\%)$ & 0.375 \\
3 & Story drift, $\Delta_{2}(\%)$ & 0.50 \\
4 & Strain in the reinforcement of the base of the walls (Bars), $\varepsilon_{\text {bar }}$ & 0.05 \\
5 & Strain in the reinforcement of the base of the walls (Meshes), $\varepsilon_{\mathrm{Ww}}$ & 0.01 \\
6 & Compressive strain of concrete at the ends of the base of the walls, $\varepsilon_{\text {conc. }}$ & 0.003 \\
\hline
\end{tabular}

Note: ${ }^{*} L_{p}=0.5 I_{w}, * * L_{p}=2.5 t_{w}$. Where $L_{p}$ : plastic hinge length, $t_{w}:$ wall thickness, and $I_{w}$ : wall length.

The acceptance criterion of the first parameter (1), rotation at the base of the walls, was taken from ASCE/SEI 41-06 (2007) for walls with axial load ratios (ALR) lower than 0.10, a mean maximum shear force lower than or equal to $0.02 \mathrm{MPa}$, and walls without confined boundary elements according to ACl 318 (2014). According to Elwood et al. (2007), the experimental results of Hidalgo et al. (2002), EERI/PEER (2006), and Wallace et al. (2006) showed that the criteria of this standard, unlike the most recent versions, are conservative for walls with well-confined special boundary elements. Therefore, they could be used for this type of thin wall. In addition, these walls meet the condition of absence of confined boundary elements because a thickness lower than or equal to $150 \mathrm{~mm}$ does not guarantee adequate concrete confinement (Arteta, 2015). The plastic hinge was evaluated according to ASCE/SEI 41, at a wall height equal to 0.5 times its length and at a height of 2.5 times the wall thickness, in line with the hinge length experimentally reported in thin wall tests (Blandón \& Bonett, 2020; Ortega et al., 2021). For the parameter story drift, two acceptance criteria were taken (2 and 3 ). The first was proposed by Gonzales and López-Almansa (2012), according to a numerical evaluation of the seismic behavior of buildings with walls of limited ductility in Peru. The second was taken according to the experimental response assessed in TRCWs tests (Rosso et al. 2015, Blandón et al. 2018, Blandón \& Bonett 2020, Carrillo \& Alcocer 2012, Ortega et al. 2021, and CEER 2018). These studies suggest that a story drift of $0.5 \%$ could be a limit of good behavior for this structural system. The limit values for strains in ductile reinforcement (4) and meshes (5), for the life safety performance level, were defined according to the rupture strain proposed by Arroyo et al. (2021) for these materials. The limit for the sixth parameter was taken as the theoretical ultimate compressive strain of unconfined concrete.

Story drifts were assessed for each accelerogram. The plastic hinge rotation and the compressive strain of concrete at the base of the walls were assessed using the tools Quad Strain Gauge and Line Strain Gauge of the software ETABS. Reinforcement steel strains were retrieved from the Shell Layered model in each wall. The results were expressed as a demand-capacity ratio (D/C) according to the limits indicated in Table 7. These results were organized in decreasing order of the mean D/C ratio of the seven earthquakes for each parameter and correspond to the maximum values of each building. The demand was calculated as the square root of the sum of the squares of the results of the components of each earthquake.

The seismic performance assessment of building E1 is summarized in Figure 10. No parameter surpassed the proposed acceptance limit. The mean D/C ratio was lower than 1 in all earthquakes (Figure 10a). Based on these results, building E1 meets the life safety performance level for a demand consistent with the design seismic hazard. Figure 10b shows the walls with maximum rotations and strains in the concrete and reinforcement steel. These walls correspond to the longest ones, which take approximately $43 \%$ and $26 \%$ of the seismic shear in the $x$ - and y-directions, respectively.

In building E2, the most critical parameter is the story drift for both limits, $\Delta 1(0.375 \%)$ and $\Delta 2(0.5 \%)$, as shown in Figure 11a. The mean $\mathrm{D} / \mathrm{C}$ ratio of story drifts $\Delta 1$ and $\Delta 2$ was great than 1 for all earthquakes, with maxima of up to 2.69 and 2.02, respectively. After the story drift, the other parameters that could be critical are the compressive strain of concrete at the base of the walls $\left(\varepsilon_{\text {conc. }}\right)$, the tensile strain of the WWM reinforcement $\left(\varepsilon_{\text {wwM }}\right)$, and the plastic hinge rotation of the walls $\left(\theta_{\mathrm{rp}}{ }^{*}\right)$. These parameters showed mean D/C ratios of approximately 0.8 , but they reached considerable values for the $\mathrm{CH}$ and JP earthquakes. The rupture strain in WWM reinforcement (0.0015) proposed by Carrillo et al. (2018) was surpassed in three walls. The parameter tensile strain of the WWM reached a maximum D/C ratio of 2.45. The walls in which the maximum strains and rotations were concentrated are indicated in Figure $11 \mathrm{~b}$. These walls take 50 and $40 \%$ of the seismic shear along the $x$ - and y-directions, respectively. 

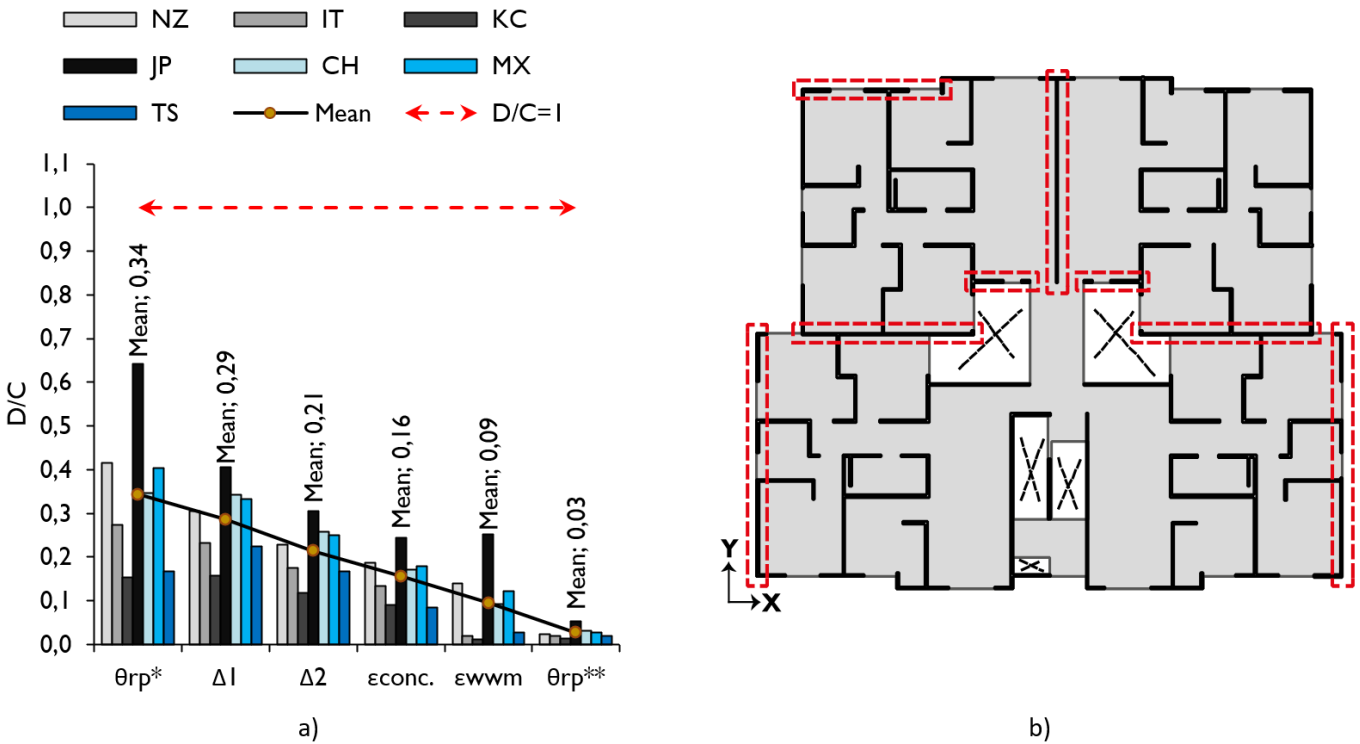

Figure 10. Seismic performance assessment of building E1: a) D/C ratio; b) critical walls.

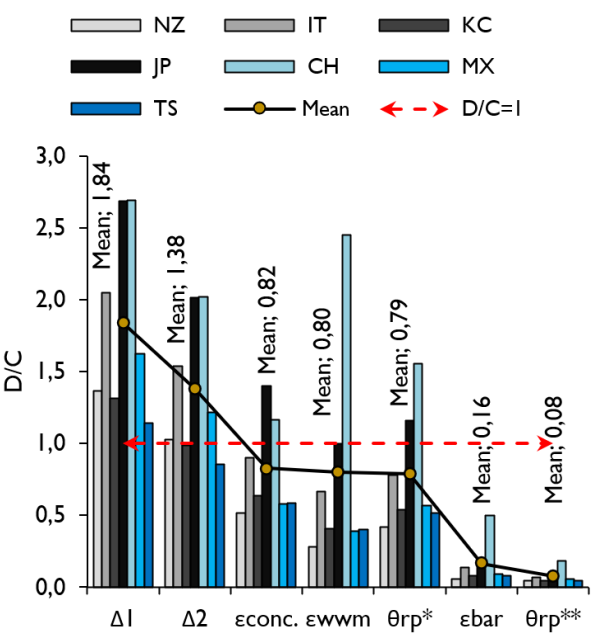

a)

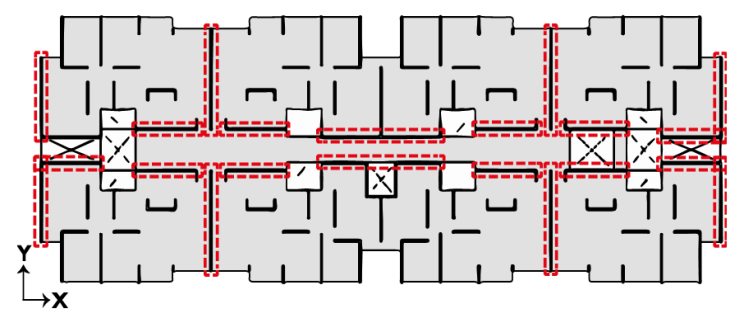

b)

Figure 11. Seismic performance assessment of building E2: a) D/C ratio; b) critical walls.

Building E3 showed a more critical performance than the 8-story building. Figure 12a shows that for the parameters $\Delta_{1}, \Delta_{2}, \varepsilon_{\text {conc., }}$, the mean $D / C$ ratios greatly exceeded 1, with values of 2.82, 2.11 and 1.62, respectively, followed by the parameters $\varepsilon_{w w m}$ and $\theta_{\mathrm{rp}}{ }^{*}$, with $\mathrm{D} / \mathrm{C}$ ratios of 0.98 and 0.9 , respectively. In this building, the demand at which the most critical results were found was that induced by the earthquake TS (Taiwan Smart1 1986). In this earthquake, natural frequencies close to $1.39 \mathrm{~Hz}(T=0.72 \mathrm{~s})$ prevailed, thus matching the natural frequency of the second mode of vibration, corresponding to the $x$-direction of the building, wherein $60 \%$ of the seismic mass was excited. One of the most critical effects on the seismic performance of this building, as in building E2, was the rupture of the WWM reinforcement in five walls. The tensile strain of the WWM reached a maximum D/C of 2.24. This result indicates that the rupture limit was reached for this type of material. This phenomenon, accompanied by high compressive demands in the concrete at the base of the walls, shows that several of the walls that significantly contribute to the seismic resistance system could suffer severe damage, leading to a significant reduction in the capacity of the structure. The most critical walls of building E3 are shown in Figure 12b. 


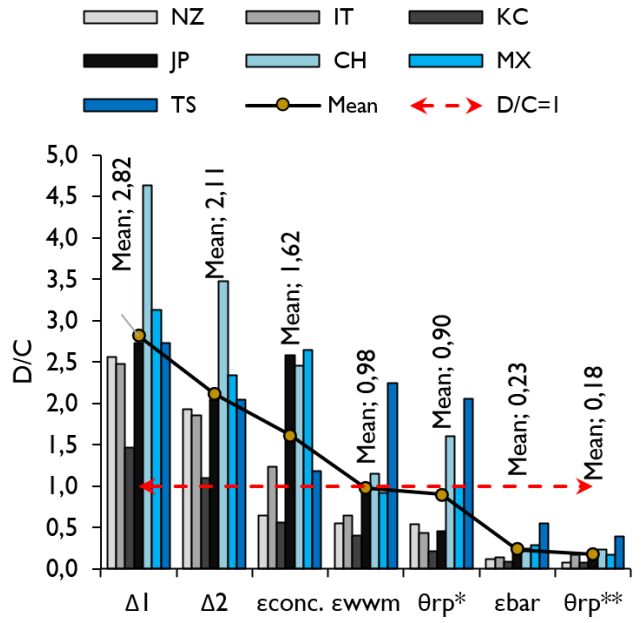

a)

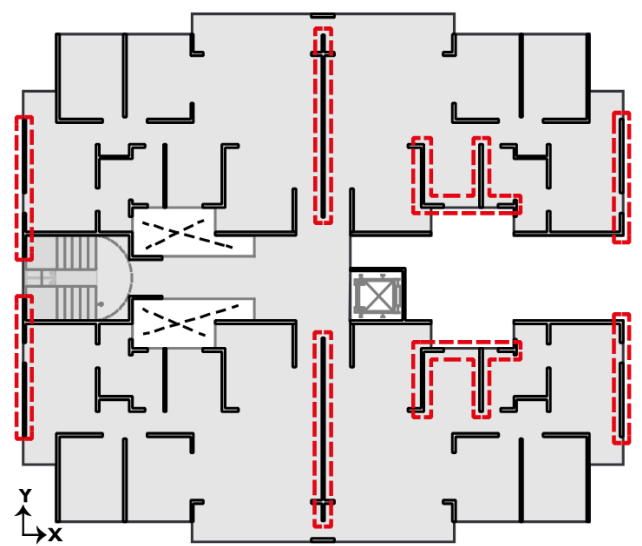

b)

Figure 12. Seismic performance assessment of building E3: a) D/C ratio; b) critical walls.

\section{PARAMETRIC ANALYSIS}

To evaluate the influence of some variables on the performance of TRCW, a parametric analysis was carried out with 140 numerical models. For this, an isolated rectangular section wall was taken, with representative characteristics of this structural system. For each variation, the capacity curve of the wall was obtained using a nonlinear static analysis (Pushover), and the seismic behavior was evaluated concerning its deformation capacity and some damage limit states. The limitations of this model are related to the coupling with other walls, the variation of the stiffness in height, and the out-of-plane buckling failure mechanism.

\subsection{Study variables}

According to the results obtained in the evaluation of the performance of buildings and what has been reported by some authors such as CEER (2018), Kazaz et al. (2012), Salonikios et al. (1999), Thomsen IV \& Wallace (1995), and Wallace \& Moehle (1992), the variables that can most influence the performance of these buildings are: i) wall thickness $\left(t_{w}\right)$, ii) aspect ratio $\left(h_{w} / I_{w}\right)$, iii) longitudinal reinforcement ratio in the wall edges $\left(\rho_{b}\right)$, iv) concrete confinement and $\left.v\right)$ axial load ratio $\left(A L R=P / f^{\prime} c_{w} t_{w}\right)$. The first three variables were evaluated in this study (Figure 13a).

Wall thicknesses of 80 and $100 \mathrm{~mm}$ for 5 -story walls, 100 and $120 \mathrm{~mm}$ for 10 -story walls, and 120 and $150 \mathrm{~mm}$ for 15 -story walls were evaluated. To analyze the effect of aspect ratio, three heights, $\mathrm{H}_{\mathrm{w}}$, corresponding to 5-, 10-, and $15-$ story buildings, and wall lengths of 1, 2, 4, and $6 \mathrm{~m}$ were taken. This results in aspect ratios of 2.1, 3.1, 4.2, 6.3, 9.4, 12.5, $18.8,25.0$ and 37.5. In all cases, a typical story height of $2.5 \mathrm{~m}$ was defined. Five values were also evaluated for the longitudinal reinforcement ratio in the wall edges, $0,1,2,3$, and $4 \%$. This steel was of the ductile type and was arranged as additional reinforcement at the ends in a single layer, following the construction practice of the industrialized system. The longitudinal reinforcement ratio of $0 \%$ corresponds to the condition of the entire wall reinforced with electro-WWM.

To consider an axial load ratio equivalent to that expected in a building, the vertical load was calculated using Equation (1). This expression was determined from the structural analysis of the linear models of the 18 representative buildings of the TRCW system.

$A L R=0.0019 H_{w}+0.007$

\subsection{Analysis considerations and limit states}

Walls cross-section and the nonlinear behavior of the materials were defined as described in the section Description of the numerical models. The rigid diaphragm condition was considered by assigning constraints to the height of the interstories. A denser mesh was used in the lower part of the wall to capture the damage in that area. For the pushover analysis, an inverted triangle-shaped lateral loading pattern was employed, consistent with the expected distribution of forces in the fundamental mode of vibration. The capacity curves obtained from the analysis are express in terms of the basal shear $\left(V_{\text {btot }}\right)$ and roof drift. On this curve, damage limit states related to strains in concrete and reinforcing steel, the first plastic hinge, drift limits for RC structural walls, and the failure point of the wall were identified. Strains were calculated at the wall 
ends, in a region between the base and up to a height of 2.5 times the wall thickness, as shown in Figure $13 b$. Roof drift was expressed as the percentage ratio in percent between the displacement at the top of the wall and the total height $\left(\delta_{\mathrm{u}} / \mathrm{H}_{\mathrm{w}}\right)$.

The yield and rupture strains of the bars were taken as 0.002 and 0.06 , respectively, according to the rupture limit proposed by CEER (2018). For the electro-welded reinforcement, the yield and rupture strains were taken as 0.0025 and 0.015 , respectively. The first plastic hinge of the wall was assumed at the instant in which the reinforcing steel, at the edges, reached a strain equal to twice the yield strain (CEER, 2018). The ultimate compressive strain of unconfined concrete was established as 0.004 . Limit drifts of $0.5,1$, and $1.43 \%$ are indicated in the wall capacity curves as a reference. In this study, the failure state is defined for the instant in which a $20 \%$ drop in lateral resistance occurs. Since this loss of capacity does not occur in all curves, two criteria were defined to establish an ultimate damage state close to failure. That is, when the strain in the bars exceeds the breaking limit or when the crushing of the concrete begins. From these events, the capacity curve of the walls was differentiated with more subdued color.

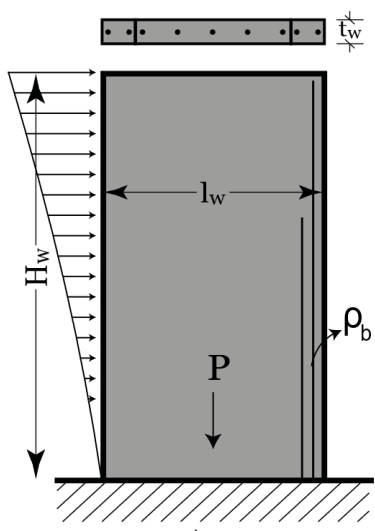

a)

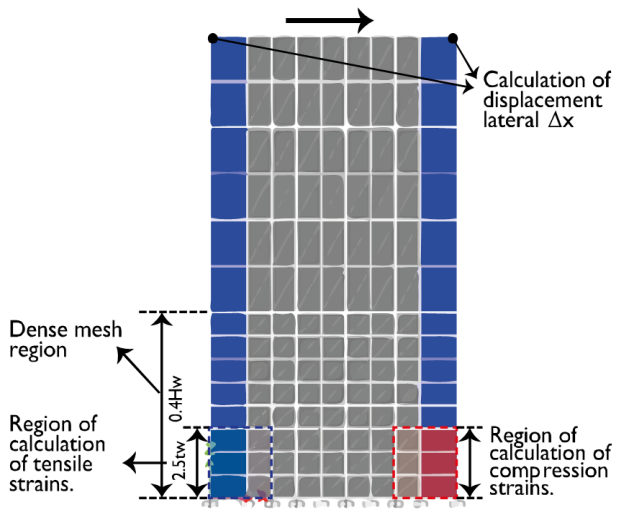

b)

Figure 13. Parametric analysis variables: a) Study variables; b) Location of response parameters.

\subsection{Results of parametric analysis}

The influence of the variables analyzed on the lateral load response of the walls is shown in Figure 14 . The curves were grouped by the number of stories, wall thickness, aspect ratio, and longitudinal reinforcement ratio in the wall edges. In general, the curves present well-defined sections, where the regions of elastic and inelastic behavior are observed. The first limit states reached correspond to the reinforcement yield, followed by the first plastic hinge (global yield point), and subsequently, the rupture of the WWM or the crushing of the concrete before reaching the maximum strength of the wall.

The observed behavior indicates that as the aspect ratio decreases, the lateral resistance increases and the displacement capacity decreases, causing the damage limit states of the materials to be reached for lower displacements. It was found that the rupture of the electro-WWM and the crushing of the concrete, in a typical $4 \mathrm{~m}$ long wall, occur for a roof drift between 0.4 and $0.8 \%$. If it is taken as a reference that the maximum story drift, according to the linear analysis of the 18 MDCR buildings, equals approximately 1.34 times the roof drift (Figure 15a), similar to what was obtained by CEER (2018), it can be deduced that the limit of good performance for these walls would correspond to a story drift close to $0.5 \%$. This coincides with what was observed in the experimental tests of isolated walls, in which, from displacements associated with drifts between $0.5 \%$ and $0.6 \%$, the level of damage begins to increase noticeably.

Walls with an aspect ratio between 2 and 10 (defined for this study as long and intermediate walls), despite having a longitudinal reinforcement ratio in the edges close to $4 \%$, exhibit limited ductility and present considerable damage, such as mesh rupture or crushing of the concrete, for drifts less than $1.43 \%$. Walls with aspect ratios greater than 10 (short walls) show low lateral load resistance and apparent ductility for drifts greater than $1.43 \%$, except those with longitudinal reinforcement ratio in the edges less than $1 \%$. These results indicate that long and intermediate walls will govern the seismic response of a building since they are the first to reach the inelastic range and that, on the contrary, short walls would not contribute significantly to the overall ductility of the structure, since they tend to respond in the elastic range for the expected seismic demand. Priestley et al. (2007) point out that an acceptable level of ductility would only be feasible for walls with low aspect ratios. The limit value for this condition could be up to 6 (CEER, 2018). For the 18 TRCW buildings analyzed in this study, it was found that the proportion of short walls is, on average, higher than $33 \%$, and as the number of stories increases, this percentage goes up to $78 \%$ in buildings with more than ten stories, as shown in Figure 15b. This suggests that the ductility of these structures may not be as expected. In these buildings of more than ten stories, the proportion of long walls $\left(A_{r} \leq 6\right)$ is only $2.7 \%$, and of intermediate walls $\left(6<A_{r} \leq 10\right)$ is $20 \%$. 


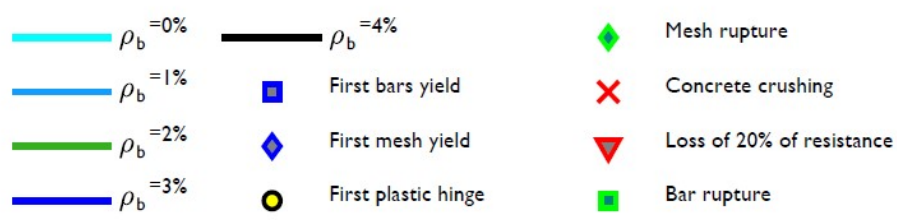

5 stories

10 stories

15 stories
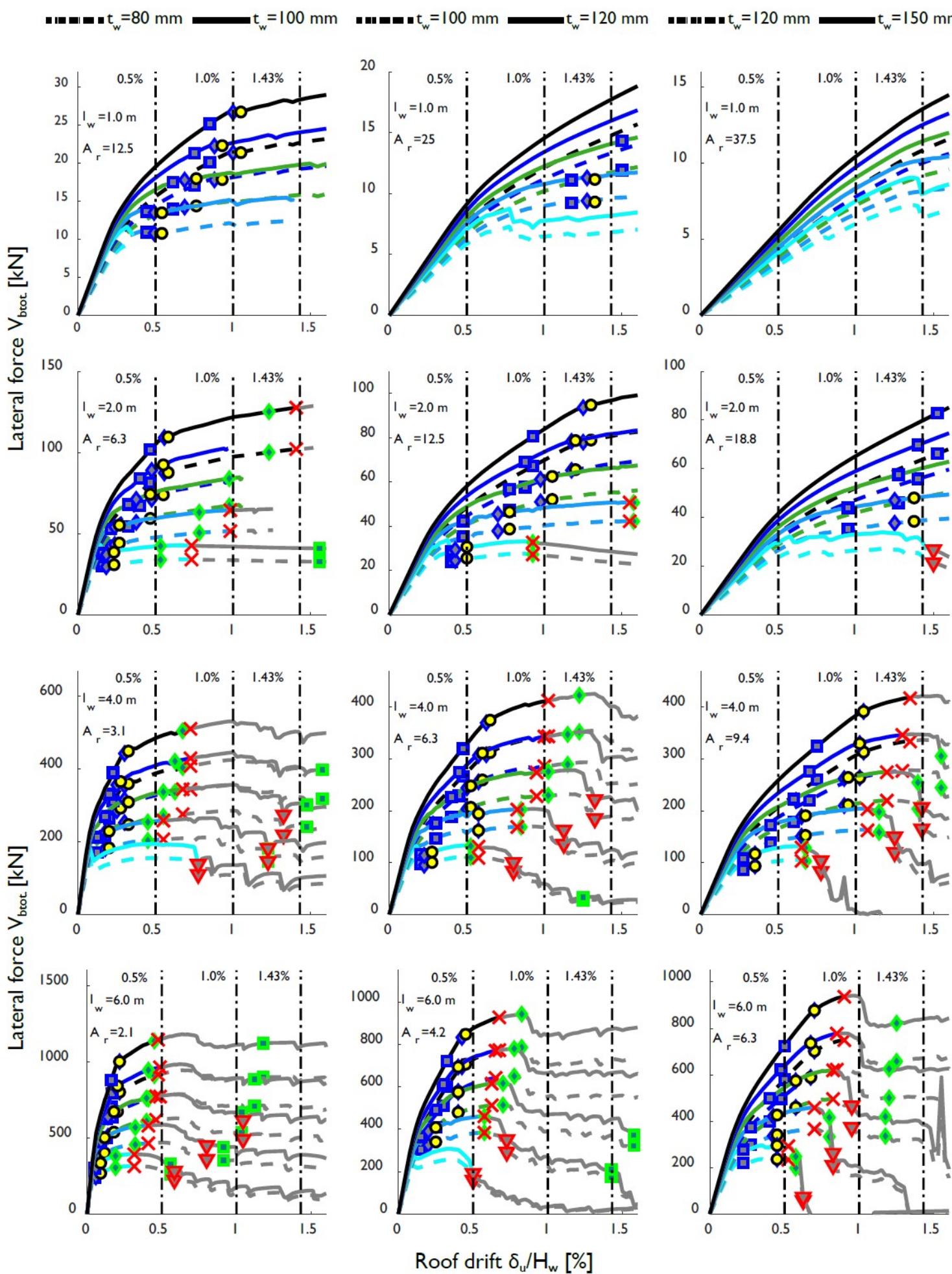

Figure 14. Capacity curves as a function of $A_{r}, \rho_{b}$ y $t_{w}$. 


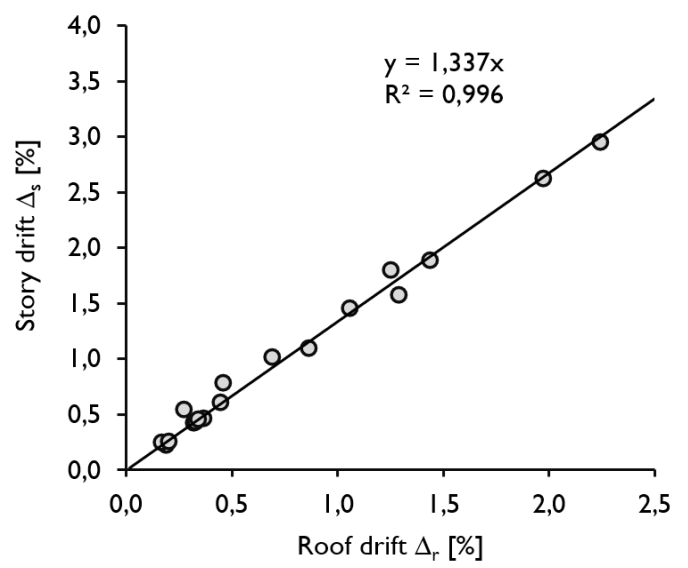

a)

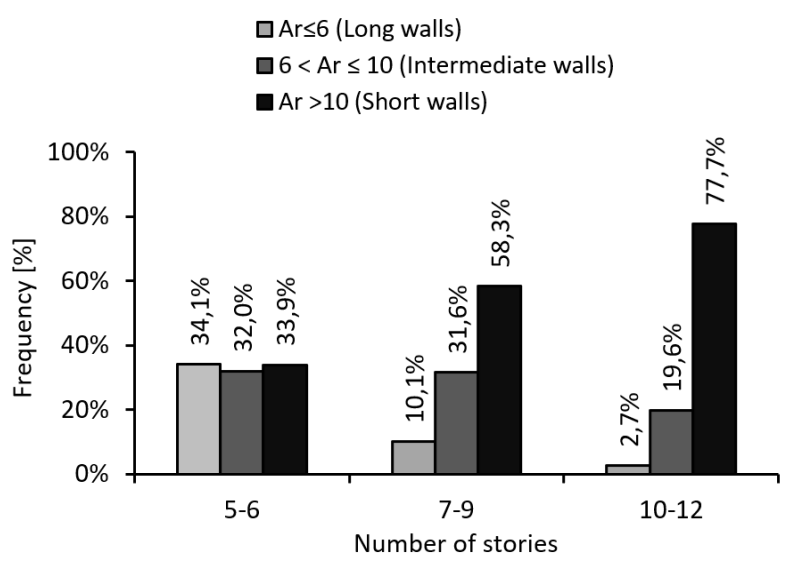

b)

Figure 15. Linear and statistical analysis of the 18 MDCR buildings: a) ratio between roof drift and maximum story drift;

b) aspect ratio.

The longitudinal reinforcement ratio in the edges has an important influence on the ductility of the walls, as shown in Figure 14. It is evident that an increase in the longitudinal reinforcement ratio at the edges increases the lateral resistance, the displacement capacity and causes the ultimate deformation of the materials to be reached for larger roof drifts. Regarding the thickness, it influences exclusively the lateral load capacity, and the stiffness of the walls, as shown in Figure 16. This is without considering other effects such as out-of-plane slenderness. Figure 16 shows, in more detail, the capacity curves for a $4 \mathrm{~m}$ long wall, with a $2 \%$ longitudinal reinforcement ratio at the edges, for the evaluated heights of 5,10 , and 15 stories. In this wall, although the variation between the evaluated thicknesses is small ( 80 to $150 \mathrm{~mm}$ ), it is observed that the damage states occur for similar drift levels between one thickness and another.
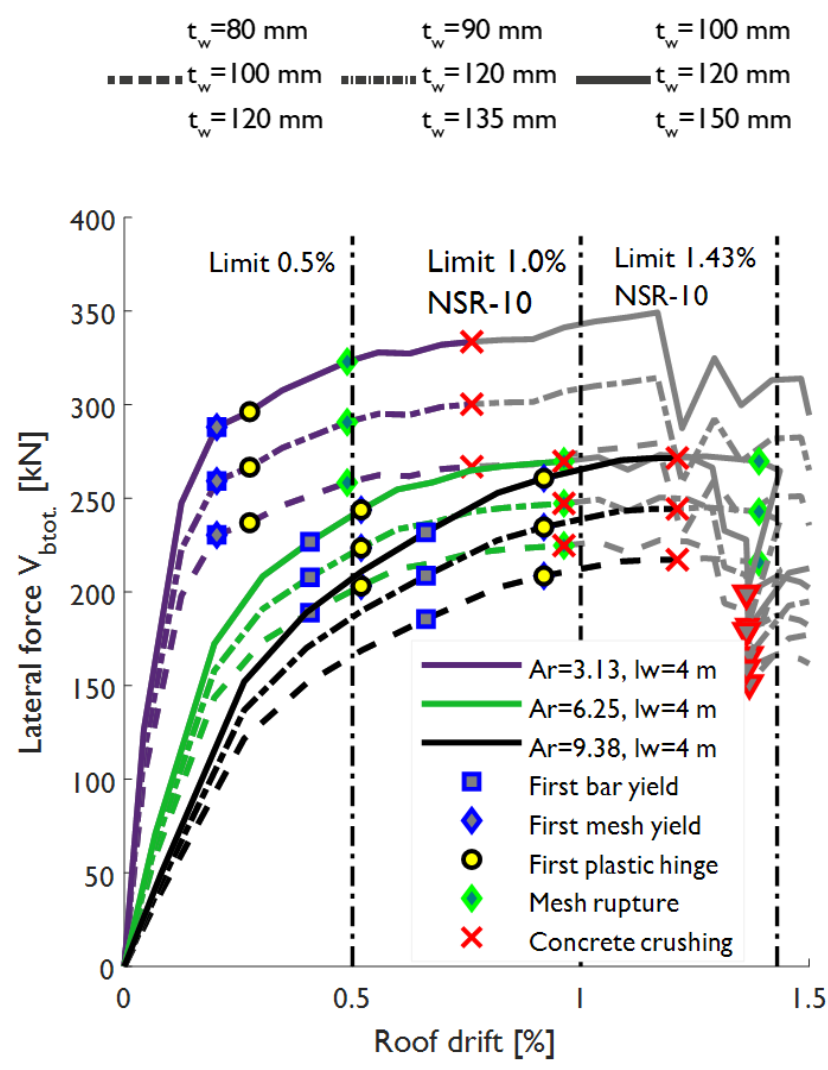

Figure 16. Capacity curves as a function of thickness. 


\section{CONCLUSIONS}

The vulnerability and seismic performance of three 5-, 8- and 12-story buildings representatives of the industrialized building system and located in a high seismic hazard area in Colombia were evaluated in this study. Nonlinear models that were fitted based on the hysteretic response of isolated walls and an ambient vibration test in one of the buildings were used. The results led to the following conclusions:

According to the seismic vulnerability assessment, the 5-story building E1 had a higher resistance and stiffness than that required by the design demand. In the 8-story building E2, several of the main walls had an OEl bending higher than 1 , which suggests that its resistance may be insufficient, mainly in the direction with the lowest density of walls. The 12story E3 building was in a more critical condition because the OSI and FlexI values indicated that both its strength and its stiffness are insufficient when facing seismic demand. The most critical direction in this building was that with the highest wall density due to the discontinuity in the floor diaphragm.

According to the seismic performance assessment, building E1 performed satisfactorily, whereas buildings E2 and E3 failed to meet the life safety performance level. The performance parameters of the 8-story building E2 exceeded the limits proposed for several study earthquakes and for the average of the earthquakes. This result was observed in several main walls of the seismic resistance system of the building. For an earthquake with characteristics similar to that which occurred in Chile in 2005 (CH) and scaled to the expected design seismic hazard for this structure, the deformation limits of the materials were exceeded by factors greater than 2 . In the 12-story building $\mathrm{E} 3$, the performance was more critical because, for a greater number of parameters and earthquakes, the $\mathrm{D} / \mathrm{C}$ ratio was higher than 1 , and higher values of the $\mathrm{D} / \mathrm{C}$ ratio were reached than those assessed for building $\mathrm{E} 2$. The most important damages to this building were the web reinforcement rupture and the considerable damage to the concrete at the base of the walls.

The most critical performance parameters, in decreasing order, for the 8- and 12-story buildings were story drift, the ultimate compressive strain of concrete at the base of the walls, and the tensile strain of the web reinforcement. This type of damage is in line with the results from experimental studies of isolated walls subjected to cyclic lateral loading (Blandón et al., 2018; Blandón \& Bonett, 2020; Ortega et al., 2021).

The model used for the numerical simulation of TRCW buildings presents some limitations related to coupling with other walls and to the possibility of failure due to out-of-plane buckling. Therefore, the findings in this study should be taken with caution. Nevertheless, the response of the structures suggests that buildings with walls constructed with the typical practices of the industrialized building system, mainly, with high slenderness ratios, without confinement at the ends of the walls, and using electro-welded wire reinforcements, could fail to meet the life safety performance level, especially buildings with eight or more stories in high seismic hazard areas.

The numerical analysis of TRCW indicates that the story drift limit of 1 or $1.43 \%$, established by NSR-10, for gross and cracked sections, respectively, is not an adequate requirement for the design of buildings with this structural system. The good performance limit for TRCWs is reached at values significantly lower than these drifts.

\section{ACKNOWLEDGMENTS}

This work is part of the research projects "Evaluación del comportamiento estructural y propuesta de reforzamiento para edificaciones existentes de muros delgados de concreto reforzado" code: 70953 - contract 463-2020 - program code: 110685270483, and "Evaluación numérica del comportamiento sísmico de edificaciones de muros delgados de concreto reforzado representativas del diseño y construcción en Colombia" of the Internal call 120 - 2019 of the Universidad del Valle. The authors would like to thank the Ministerio de Ciencia, Tecnología e Innovación (MinCiencias) and Universidad del Valle, entities that funded the projects.

Authors contributions: Conceptualization (equal), Methodology (equal), Investigation (equal), Writing - original draft (equal), Writing - review and editing (equal); E Cuesvas, R Ortega, J Marulanda, P Thomson, G Areiza and A Cruz.

Editor: Pablo Andrés Muñoz Rojas

\section{References}

ACl Committee 318. (2014). Building Code Requirements for Structural Concrete (ACl 318-14) and Commentary (ACl 318R-14). In ACl 318-14. American Concrete Institute. 
AIS. (2010). Reglamento Colombiano de Construccion Sismo Resistente "NSR-10". Asociación Colombiana de Ingeniería Sísmica.

Arroyo, O., Feliciano, D., Carrillo, J., \& Hube, M. A. (2021). Seismic performance of mid-rise thin concrete wall buildings lightly reinforced with deformed bars or welded wire mesh. Engineering Structures, 241, 1-12.

https://doi.org/10.1016/j.engstruct.2021.112455.

Arteta, C. A. (2015). Seismic Response Assessment of Thin Boundary Elements of Special Concrete Shear Walls [University of California]. https://escholarship.org/uc/item/98384265.

ASCE/SEI 41-06. (2007). Seismic Rehabilitation of Existing Buildings. American Society of Civil Engineers.

ASCE/SEI 41-17. (2017). Seismic evaluation and retrofit of existing buildings. American Society of Civil Engineers.

Blandón, C., Arteta, C. A., Bonett, R. L., Carrillo, J., Beyer, K., \& Almeida, J. P. (2018). Response of thin lightly-reinforced concrete walls under cyclic loading. Engineering Structures, 176(August), 175-187.

https://doi.org/10.1016/j.engstruct.2018.08.089.

Blandón, C., \& Bonett, R. (2020). Thin slender concrete rectangular walls in moderate seismic regions with a single reinforcement layer. Journal of Building Engineering, 28(October 2019). https://doi.org/10.1016/j.jobe.2019.101035.

Carrillo, J., \& Alcocer, S. (2012). Aceptance limits for performance-based seismic design of RC walls for low-rise housing. Earthquake Engng Struct. Dyn., 1-16. https://doi.org/10.1002/eqe.2186.

Carrillo, J., Diaz, C., \& Arteta, C. A. (2018). Tensile mechanical properties of the electro-welded wire meshes available in Bogotá Colombia. Construction and Building Materials, 195, 352-362. https://doi.org/10.1016/j.conbuildmat.2018.11.096.

CEER. (2018). Estudio del Comportamiento Sísmico de Edificios de Muros Delgados de Concreto Reforzado (Issue 002).

CSI. (2017). CSI Analysis Reference Manual. In Computers \& Structures (Edición 19).

Cuesvas, E., Ortega, R., Torres, P., Marulanda, J., \& Thomson, P. (2020). Simulación numérica del comportamiento sísmico de muros de concreto reforzado. In Instituto Antioqueño de Investigación (Ed.), InGENIO 2020, Congreso Latinoamericano de Ingeniería. http://fundacioniai.org.

DANE. (2021). Censo de edificaciones (CEED).

Doweel, R. K., Seibe, F., \& Wilson, E. L. (1998). Pivot Hysteresis Model for Reinforced Concrete Members. ACI Structural Journal, 95(5).

EERI/PEER, 2006, New Information on the Seismic Performance of Existing Concrete Buildings, Seminar Notes, Earthquake Engineering Research Institute, Oakland, California.

Elwood, K. J., Matamoros, A. B., Wallace, J. W., Lehman, D. E., Heintz, J. A., Mitchell, A. D., Moore, M. A., Valley, M. T., Lowes, L. N., Comartin, C. D., \& Moehle, J. P. (2007). Update to ASCE/SEl 41 concrete provisions. https://doi.org/10.1193/1.2757714.

FEMA 356. (2000). FEMA 356 Prestandard (Issue November, p. 519).

Gonzales, H. F., \& López-Almansa, F. (2012). Seismic performance of buildings with thin RC bearing walls. Engineering Structures, 34, 244-258. https://doi.org/10.1016/j.engstruct.2011.10.007.

Hidalgo, P. A., Ledezma, C. A., \& Jordan, R. M. (2002). Seismic behavior of squat reinforced concrete shear walls. Earthquake Spectra, 18(2), 287-308. https://doi.org/10.1193/1.1490353.

INGEOMINAS. (2005). Report 4: Investigaciones y Zonificación Geotécnica de la Ciudad de Santiago de Cali.

Kazaz, I., Gülkan, P., \& Yakut, A. (2012). Deformation limits for structural walls with confined boundaries. Earthquake Spectra, 28(3), 1019-1046. https://doi.org/10.1193/1.4000059.

Mander, J. B., Priestley, M. J. N., Park, R., Fellow, \& ASCE. (1988). Theoretical stress-strain model for confined concrete. 114(8), 1804-1826.

Oesterle, R. G., Fiorato, A. E., JohaL, L. S., Carpenter, J. E., Russell, H. G., \& Corley, W. E. (1976). Earthquake Resistant Structural Walls- Tests of Isolated Walls; Appendix A - Experimental Program; -Apendix B - Test Results.

Ortega, R., Naranjo, C., Torres, P., Madera, C., Marulanda, J., Thomson, P., \& Areiza, G. (2021). Evaluation and fitting of a numerical model for reinforced concrete thin walls through experimental results of monotonic and cyclic loading tests. Latin American Journal of Solids and Structures, 21. 
Ortega, R., Torres, P., Cuesvas, E., Cruz, A., Marulanda, J., \& Thomson, P. (2019). Análisis Estadístico de Edificaciones de Muros Delgados de Concreto Reforzado en Zona de Amenaza Sísmica Alta : Casos Cali y Popayán. IX Congreso Nacional de Ingeniería Sísmica, Mayo 2019, 1443-1458.

Palacios, V. J. M. (2017). Caracterización de edificaciones construidas con el sistema de muros delgados de concreto reforzado en Santiago de Cali. Universidad del valle.

Park, R., \& Paulay, T. (1975). Reinforced concrete structures. In Wiley - Interscience. https://doi.org/10.1201/b19154-3.

Priestley, M. J. N., Calvi, M. C., \& Kowalsky, M. J. (2007). Displacement-Based Seismic Design of Structures. IUSS Press, Pavia.

Quiroz, L. G., Maruyama, Y., \& Zavala, C. (2013). Cyclic behavior of thin RC Peruvian shear walls: Full-scale experimental investigation and numerical simulation. Engineering Structures, 52, 153-167.

Rosso, A., Almeida, J. P., \& Beyer, K. (2015). Stability of thin reinforced concrete walls under cyclic loads: state-of-the-art and new experimental findings. Bulletin of Earthquake Engineering, 14(2), 455-484. https://doi.org/10.1007/s10518-015-9827-x.

Salonikios, T. N., Kappos, A. J., Tegos, I. A., \& Penelis, G. G. (1999). Cyclic load behavior of low-slenderness RC walls - Design basis and test results. ACI Structural Journal, 96(4), 649-661.

S. Mirza, J. MacGregor, Strength and ductility of concrete slabs reincforced with welded wire fabric, ACI J. 78 (33) (1981) 374-381.

Thomsen IV, J. H., \& Wallace, J. W. (1995). Displacement-Based Design of Reinforced Concrete Structural Walls: An Experimental Investigation of Walls with Rectangular and T-Shaped Cross-Sections. In National Science Foundation. http://nisee.berkeley.edu/elibrary/Text/200606122.

Wallace, J., Massone, L., and Orackal, K., 2006, "St. Josephs Healthcare Orange, California SPC- 2 Upgrade: E/W Wing Component Test Program," UCLA SEERL Report 2006/01, Department of Civil and Environmental Engineering, University of California, Los Angeles, 10 pp.

Wallace, J. W., \& Moehle, J. P. (1992). Ductility and Detailing Requirements of Bearing Wall Buildings. Journal of Structural Engineering, 118(6), 1625-1644. https://doi.org/10.1061/(asce)0733-9445(1992)118:6(1625) .

Xie, L., Lu, X., Lu, X., Huang, Y., \& Ye, L. (2014). Multi-Layer Shell Element for Shear Walls in OpenSees. Computing in Civil and Building Engineering. 